\title{
IMMUNOPROPHYLAXIS REDUCTION EFFECTIVENESS IN ELDERLY DETERMINED BY IMMUNE RESPONSE SENESCENCE
}

\author{
Cruz ${ }^{2,3 .}$ Cynthia Mafra Fonseca de Lima ${ }^{2,4}$ \\ ${ }^{1}$ Anhembi Morumbi University (UAM), Sao Paulo, Brazil. \\ 2 University Center CESMAC, Alagoas, Brazil. \\ 3 University Center UNIT, Alagoas, Brazil. \\ 4 Federal University of Alagoas (UFAL), Alagoas, Brazil.
}

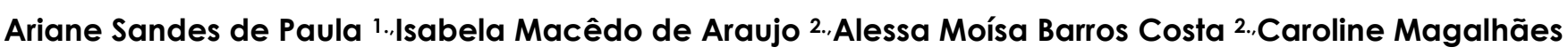

Tenório Rocha Sobrinho 2.João Rubens Ribeiro Figueira 2.Marcos Reis Gonçalves 3.Cristiane Monteiro da

(Received on Date: 5 March 2021

Date of Acceptance: 13 March 2021

Date of Publish: 19 March 2021)

E-mail: mafracynthia@hotmail.com

\section{ABSTRACT}

The immune system is responsible for ensuring the individual protection by the recognition and combat of infections and cancer cells, tissue healing process control and the separation of an individual's antigens from potentially pathogenic microorganisms. In this sense, immunological senescence has been associated with most age-related comorbidities and with the reduction in response to vaccination. Thus, the aim is to analyze the changes associated with immunosenrescence and to outline the consequences on the response to vaccination for the elderly individuals is necessary. For this, an integrative review of the literature was performed in the Medline (via Pubmed), Lilacs (via BVS) and ScienceDirect databases. Descriptors found in MeSH and DeCS, associated with OR and AND Boolean operators, were used. After applying filters to articles published between 2015 and 2020, 2,088 articles were found and submitted to the election criteria with 40 articles selected. Sudies have shown that aging induces changes in immune function affecting both the functionality and number of immune cells. Therefore, although the response capacity to vaccination is reduced in the elderly, the act of vaccination remains fundamental, since it strengthens immune responses and improves clinical results.

Key-words: Immunosensing; Vaccination; Elderly; Immunization programs. 


\section{INTRODUCTION}

The number of elderlies is in constant growth, with a proportion of $10 \%$ in 2000 and an estimated $22 \%$ by 2050 (BAUER \& FUENTE, 2016; CIABATTINI et al., 2018). It is believed that Brazil will occupy the sixth position among the countries with the highest population aging rate until the year 2025, according to the World Health Organization (WHO). The increase in life expectancy, however, may have a negative socioeconomic impact in some countries, since the elderly live with multiple comorbidities attributed to aging (ALVES \& BUENO, 2019).

It is well known that the functional immune system is responsible for ensuring the individual protection from the recognition and combat of infections and cancer cells, tissue healing process control, in addition to separating the individual's own antigens (self) from potentially pathogenic microorganisms (WEYAND \& GORONZY, 2016). Thus, the increased susceptibility to various diseases in the elderly, as well as the poor response to vaccination, is closely linked to poor immune functioning leading to an increase in hospital admissions numbers (ALVES \& BUENO, 2019).

Simply put, the immune response presents itself as innate and adaptive immunity, which are interdependent. In this sense, the innate response failure can affect the adaptive functioning and vice versa (BULATI et al., 2017). It is worth noting that, in the context of aging, adaptive immunity is more susceptible to change when compared to innate immunity (PAGE et al., 2018).

During the aging process the organism is affected by a state of oxidative stress and chronic inflammatory, causing a decline in physiological function. From this point of view, immunological senescence has been associated with most age-related comorbidities, such as osteoporosis, Alzheimer's disease, cancer, diabetes, cardiovascular, autoimmune and infectious diseases as well as a reduction in response to vaccination (BULATI et al., 2017; CROOKE et al., 2019). This study aims to analyze the functioning of innate and adaptive immune responses in the context of immunosuppression, as well as to delineate the consequences of immunological changes in the response to vaccination in elderly individuals.

\section{METHODOLOGY}

A literature review was performed in Medline (through PubMed), LILACS (through BVS) and ScienceDirect databases, as well as in the official website of the Ministry of Health. The search strategy was based on the definition of population, intervention, context and outcomes (PICO), using the descriptors (MeSH and DeCS) and free terms: "elderly", "aging", "immunosenescence", "immunology", "immune", "immunity", "lymphocyte", "innateimmunity", "thymicatrophy", "neuro", "endocrine", "vitamin D" and "vaccination", with the help of Boolean operators OR and AND. This study used articles published during the period from 2015 to 2020, without further restrictions regarding the type of study or language.

The extraction of data was based on individual analysis among researchers in order to understand the relationship between immunosuppression and the reduction of response capacity to 
vaccination in the elderly. The research steps were based on (1) selection of the most relevant titles; (2) selection of the relevant abstracts; (3) reading of the full texts and (4) choice of articles to compose the review. The eligibility criteria consisted of the articles that address the impacts of immunosuppression on the quality of life of the elderly and the immunological mechanisms involved in the vaccination process in this population. The exclusion criteria was based on articles that report on a specific organism system, immune response in young or adult individuals, genetic focus, and strictly qualitative studies.

Finally, the analysis of the data contemplated the immune system function, the immunosenrescence, the changes in innate and adaptive immunities, the response to vaccination during the aging process and the vaccination calendar of the elderly.

\section{RESULTS AND DISCUSSION}

Following the data extraction steps, 2088 articles were found in the databases after the search strategies application. Then, $88.27 \%$ of articles were excluded after reading the titles, $6.23 \%$ withdrawn after reading the abstracts and finally $3.59 \%$ excluded after reading the full text. Thus, a total of $1.91 \%$ of articles and the National Vaccination Calendar of the Brazilian Immunization Society (SBIm) were included in this study. The selection criteria are detailed in the flow chart found in figure 1 .

Among the selected articles, $37.5 \%$ have as main theme the impacts of immunosenescence on the functioning of the immune system in general; $22.5 \%$ show the vaccine response in the elderly;
$15.0 \%$ focus on changes in adaptive immunity during aging, $15.0 \%$ on the neuro-immuno-endocrine system, $7.5 \%$ on the role of vitamin $D$ in the immune system and $2.5 \%$ on innate immunity.

\section{Immune system functioning}

The immune system is responsible for the homeostasis of the human organism against infections, being able to recognize and eliminate pathogenic signs. Several components are involved in the body's defense and its good performance guarantees the body's homeostasis (HOTAMISLIGIL, 2017). Throughout life there are changes in immune profiles, therefore there is a specific regulation of the immune system by age (JOACHIM \& KOBZIK, 2018).

There are over 1600 genes involved in immune responses, which are essential to sustain life in a hostile environment. At birth, the human being has a relatively immature immune system which evolves and modulate as he is exposed to the antigens from infancy to advanced age. (SIMON et al., 2015).

The process of immunosenescence refers to the immune system decline associated with aging (PERA et al., 2015). With age there is an imbalance between inflammatory and anti-inflammatory mechanisms, which, added to hormonal changes, nutritional deficiencies and physical inactivity, leads to a strong association between advanced age and emergence of chronic diseases, as well as reduction of bone mass and greater risk of viral and acute bacterial infections. Hence the knowledge of the particularities of the immune system of the elderly importance. (HOTAMISLIGIL, 2017). 
The defense mechanisms common to all age groups can be briefly summarized in anatomical barriers, such as skin, and two types of immunity, the innate and the adaptive, which work cooperatively (VENTURA et al., 2017). Innate immunity, also called natural, is composed of macrophages, neutrophils, dendritic cells, natural killer cells (NK), cytokines and plasmatic proteins, as proteins of the complement system, being in the front line, acting in a quick way (FULOP et al., 2016; PINTI et al., 2016).

Adaptive immunity is slower but highly specific, consisting of the $T$ lymphocytes, which can be auxiliary $T$ lymphocytes (LTCD4+), also called helper, or cytotoxic T lymphocytes (LTCD8+); and the B lymphocytes, which are the antibody-producing cells. The T helper or $\mathrm{T}$ helper lymphocytes are activated and differentiate into different subpopulations, such as Th1 or Th2 type responses, that have different performing functions (VENTURA et al., 2017).

The acquired immunity activation occurs by the action of dendritic cells, which will present these foreign antigens to LTDC4+ and LTCD8+ virgin or naive, which circulate through the secondary lymphoid organs, such as spleen and lymph nodes, so that they differentiate into T effector lymphocytes and can fight the foreign antigens (BARREDA et al., 2016).

The immune system generally assembles an attack response to components considered non-self that are not inherent to the host itself (HOTAMISLIGIL, 2017). Besides infectious microorganisms, the immune system also recognizes as non-self tumors and antigens from transplanted grafts from donors not compatible with the recipient (SCHAENMAN et al., 2018). However, in some pathological cases where there is a failure in the process of physiological tolerance to the self the immune system mounts an attack against host components, causing autoimmune diseases (HOTAMISLIGIL, 2017).

When the immune system is unable to mount an effective immune response against invading infectious agents, it is called immunodeficiency (BEKTAS et al., 2017). This can be congenital, also called primary, when a genetic alteration triggers a defect in the immune system, or a secondary immunodeficiency where the individual is born with the immune system in perfect function, but begins to manifest compromises in the immune response, which can be secondary to a biological complication of another disease or to an iatrogenic one (PATEL et al., 2019).

\section{Immunosenescence}

Aging is a complex phenomenon that leads to numerous changes in the body's physiological systems. One of the most important changes, called immunosenescence, occurs in the immune system (FULOP et al., 2016) and refers to the immune system decline associated with aging (WEYAND \& GORONZY, 2016). However, the most important characteristic of immunosenescence is the accumulation in the "immune space" of memory and effector cells, as a result of stimulation caused by repeated clinical and subclinical infections and by continuous exposure to antigens (BAUER \& FUENTE, 2016; VENTURA et al., 2017). Thus, 
immunosescence is characterized as a new concept that reflects the restructuring changes associated with the age of innate and adaptive immune functions (FUENTES et al., 2017). The impact of age on immunity is nefarious, with all forms of deregulated responses attributed to immunosescence (Figure 2) (PAWELEC, 2018). It is worth noting that immunosenrescence is a physiological condition, while immunodeficiencies are pathological conditions (BEKTAS et al., 2017).

This immunological senescence makes the elderly predisposed to greater risk of acute viral and bacterial infections. The aging process comprises the set of structural and functional changes in the immune system that can manifest themselves in various ways such as: decreased capacity to fight infections, decreased response to vaccination, increased incidence of cancer, higher prevalence of autoimmunity and low grade constitutive inflammation, among others manifestations (AKHA, 2018; XU \&
LARBI,
2017).
Consequently, immunosensing implies changes in innate and adaptive immune systems and is associated with low grade inflammation, contributing to the development of agerelated diseases (PAWELEC, 2018).

At the same time, the aging of the immune system reduces the ability to maintain tolerance to autoantigens, leading to a higher autoimmune diseases incidence. For that reason, in addition to intrinsic changes in innate and adaptive immune cells, changes in the stromal microenvironment in primary and secondary lymphoid organs play an important role in age-associated immune dysfunction (AKHA, 2018; VENTURA et al.,
2017). This is believed to be due to the lymphopenia that occurs with aging, stimulating an excess of lymphocyte proliferation and homeostasis disorders, in addition to a decrease in $T$ cell function and a decrease in the clearance of apoptotic cells that is performed by macrophages (PERA et al., 2015). It is important to note that leukocytes accumulate reactive oxygen species during the aging process, causing damage to the body by oxidative stress (BAUER \& FUENTE, 2016).

The ability of the elderly in delaying the undesirable effects of aging may depend on genetic background, lifestyle, geographic region, and other currently unknown factors (BISCHOF et al., 2019). Therefore, that is a need for a better understanding of the multiple biological phenomena that lead to these diseases through the immunosensing associated with inflammation to provide a powerful target of interventions that can thus increase life expectancy of the elderly (FULOP et al., 2016). The main changes associated with immunosenescence and its consequences are detailed in figure 3.

\section{Innate immunity changes}

From the immunological senescence a functional deterioration of several innate immune components occurs, such as macrophages and dendritic cells (GUBBELSBUPP et al., 2018). Aging leads to physiological changes observed in the skin, such as reduction of sweat production, epithelial tissue structural changes, cell replacement decrease and subcutaneous layer atrophy. These changes reduce pathogens combat effectiveness and 
increase the risks of diseases, such as varicella zoster virus reactivation (SIMON et al., 2015; FUENTES et al., 2017).

Macrophages are responsible for phagocytosis (ingestion and destruction of pathogens) and the synthesis of inflammatory cytokines, in addition to presenting antigens for LTCD4+ effectors (VENTURA et al., 2017; GUBBELSBUPP, 2018). On the other hand, during the senescence process, the functional capacity of these cells is compromised (FUENTES et al., 2017).

Neutrophils also do phagocytosis and are the first cellular defenders against bacterial and fungal invaders. They can produce reactive species of nitrogen and oxygen, and other means of eliminating pathogens. The senescent neutrophil is less functional, presenting diminished phagocytic capacity (GUBBELSBUPP, 2018). In addition, neutrophils from elderly are characterized by a reduced ability to migrate to a chemotactic signal, which can lead to reduced neutrophil migration from inflamed tissue, contributing to increased local inflammation (PINTI et al., 2016).

NK cells are part of the innate type 1 lymphoid cells (ILC1) group and are responsible for the infected cells destruction by intracellular pathogens (PERA et al., 2015). In addition, they participate in the production of gammainterferon (INF-Y) which, among other functions, stimulate the microbicidal activity of macrophages and induce the activation of LTCD8+ (PINTI et al., 2016). Although the amount of NK cells increases with age, there is a decrease in their cytotoxic capacity and secretion of INF-Y (PERA et al., 2015).
The dendritic cell is crucial for the acquired response initiation, through the activation of naive lymphocytes during the presentation of antigens (GUBBELSBUPP, 2018; PINTI et al., 2016). At senescence, a functional deficiency is observed, with reduced antigenic presentation capacity, leading to a loss of T-lymphocyte-mediated response (SIMON et al., 2015). In agreement, studies have shown that elderly mice have dendritic cells with little capacity to induce a cytotoxic response of TCD8 cell (FUENTES et al., 2017).

The increase in the number of senescent cells due to decreased phagocytosis removal is therefore compromised and may contribute to the pro-inflammatory phenotype (PINTI et al., 2016). Possibly, the most critical change in innate immune system aging is the increase of pro-inflammatory cytokines IL$1 \beta, I L-6, I L-18$ and TNF-a (BEKTAS et al., 2017), characterizing the chronic inflammatory state of the elderly (PINTI ef al., 2016; FUENTES et al., 2017). It is worth noting that there is an increase in the activity of NFkB, which may contribute to enhance the release of such cytokines (ALVES \& BUENO, 2019; PINTI et al., 2016). Additionally, some studies have shown that high levels of IL-6, TNF-a and C reactive protein are related to the development of several pathologies etiology such as diabetes and cancer in elderly (BAUER \& FUENTE, 2016; FULOP ef al., 2016).

Most immune system cells have a notorious change in signaling, which is fundamental for the integration of molecular functions that converge from surface receptors to an effective response (PINTI et al., 2016). In this 
perspective, the aging process is accompanied by a negative regulation of the toll-like receptors (TLR) and nodular receptors (NLRs), reducing the ability to recognize invasive or own antigens (FUENTES et al., 2017). Such deregulation can cause altered chemotaxis, free radical production, and cell death, as well as decreased antigen presentation by dendritic cells (PINTI et al., 2016).

\section{Adaptive immunity modifications}

During childhood the thymus is hypertrophied (ALVES \& BUENO, 2019) and in adult life it suffers a reduction in size, as well as substitution of thymic tissue by fatty tissue (ODINOKOV \& HAMBLIN, 2018). This implies a worsening of the production and maturation of $T$ lymphocytes by this lymphoid organ (CEPEDA \& GRIFFITH, 2018).

The increase in comorbidities due to the decline of the immune system is a direct consequence of irregular adaptive immunity in elderly (BAUER \& FUENTE, 2016). The low number of naive $T$ cells in relation to mature $T$ cells is a consequence of thymus involution (BISCHOF et al., 2019; MAJUMDAR \& NANDI, 2018). Age-induced lymphopenia implies a reduction in the ability to establish memory in response to new antigens, compromising the efficiency of vaccines (CEPEDA \& GRIFFITH, 2018; MAJUMDAR \& NANDI, 2018). It is also observed a commitment in cytokine production by LTCD4+ (CROOKE et al., 2019; BEKTAS et al., 2017) and an inversion in the LTCD4+/LTCD8+ ratio (PAGE et al., 2018).

It is also known that naive cell reduction is more pronounced in TCD8 lymphocytes when compared to TCD4, since at 70 years of age the proportion of naive TCD8 cells is $10 \%$, while naive TCD4 cells correspond to $40 \%$ of the total cells of the group. Throughout life, $T$ cells undergo several division processes until they reach replicative senescence, becoming allergic cells, with shortened telomeres, altered phenotype and apoptosis resistance (BAUER \& FUENTE, 2016; PERA et al., 2015). In turn, the shortening of telomeres leads to a reduction in the release of IL-2, further hindering the proliferative process of these cells (ALVES \& BUENO, 2019).

In addition to the decreased production of naive and memory $T$ cellmediated responses that keep various latent viruses, such as Epstein-Barr Virus (EBV) and cytomegalovirus (CMV), in check, there is also a reduced scope for the development of specific LTCD8+ to combat other potentially lethal viruses (XU \& LARBI, 2017; BARREDA et al., 2016).

Among the factors that influence the decrease in virgin T cells, there is also the reduction in co-stimulatory molecule CD28 expression and the TCR variety with age, increasing the risk of generating oligoclonal cells (ALVES \& BUENO, 2019; PAGE et al., 2018). In addition, increased expression of prostaglandin E2 (PGE2) is observed, which, in turn, has suppressive capacity on $T$ cells from the inhibition of IL-2 release. In parallel, TCD4 cells assume a predominant Th17 phenotype, resulting in an increased Th17/Treg ratio and, consequently, an increased risk of autoimmune diseases (BISCHOF et al., 2019).

Over time, TCD8 lymphocytes (naive, effector or memory) promote increased release of pro-inflammatory 
cytokines, such as IFN-y, IL-2 and TNF-a, contributing to chronic low-grade inflammation. On the other hand, antiinflammatory cytokines are only increased in memory TCD8 cells (BEKTAS et al., 2017).

The main function of B lymphocytes is to evolve into plasma cells and produce antibodies. When activated, they can differentiate into memory cells or plasma cells (BULATI et al., 2017). Plasmacytes are the only antibodyproducing cells that in turn destroy pathogens by binding to them, primarily by facilitating phagocytosis and activating the complement system (CROOKE et al., 2019).

With aging there is a depletion in the production of $B$ lymphocytes and changes in their differentiation process, and a lower production of antibody (VENTURA et al., 2017; BISCHOF et al., 2019), although the immunity to antigens presenting to memory cells is conserved in them. (BULATI et al., 2017). Therefore, while the number of peripheral $B$ cells does not decrease with age, similarly to $T$ lymphocytes (CROOKE et al., 2019), naive $B$ cells are replaced by memory cells, which accounts for the reduction in circulating IgM levels as well as the increase in IgG, especially $\lg G 1, \lg G 2$, and IgG3 (BAUER \& FUENTE, 2016; BISCHOF et al., 2019).

In general, changes in $\mathrm{T}$ and $\mathrm{B}$ cell compartments in peripheral lymphoid organs hinder the adequate immune response to new acute pictures, latent viral infections, and vaccinations (PERA ef al., 2015; FUENTES et al., 2017). The innate immune response also decreases with age (PAGE et al., 2018). Changes in the number of innate cells are observed, with hematopoiesis skewing towards myeloid lineages (XU \& LARBI, 2017). The modifications that occur in the cells of the immune system during aging are detailed in Figure 4.

Speaking of immune senescence, the molecular and cellular particularities is still not well understood. Three phenotypes characterize senescent cells: 1- telomere attrition, leading to defects in cell division (ALVES \& BUENO, 2019); 2increased

mitochondrial burden/dysfunction and oxygen-reacting species (VENTURA et al., 2017) and 3senescence-secretory-associated

phenotype (SASP), characterize by the senescent cells secretion of chemokines, pro-inflammatory cytokines, and proteases . (BULATI et al., 2017).

Senescent late-stage $T$ cells have shorter telomeres, show decreased proliferation upon activation, but still exhibit potent effector functions, (XU \& LARBI, 2017) and they also accumulate in patients with old age, autoimmune diseases or chronic viral infections (BEKTAS et al., 2017). The mitochondrial dysfunction characteristic of senescent cells can be restored by administering antioxidants (BAUER \& FUENTE, 2016). Oxidative stress causes DNA breaks and may be the cause of telomere attrition, thus linking the first two causes of cellular aging (FUENTES et al., 2017).

\section{Neuro-immuno-endocrine system}

Aging entails changes in different systems of the body, as well as in the relationship between them, such as neuro-immuno-endocrine communication. Such modifications result from factors like variations in cellular 
matrix composition, decreased ability to maintain homeostasis, decline in immune surveillance and inflammatory repair mechanisms (KLOET, 2017; GROEF et al., 2015).

The immune system and the central nervous system (CNS) are known to interact and influence each other in various physiological processes, such as development, homeostasis, sickness, and aging (CODER et al., 2017; LIANG et al., 2017). Thus, $T$ cells can act in both pathogenesis and healing processes in the CNS, for example regulatory $T$ cells that have the ability to inhibit neuronal inflammation and protect against neurodegenerative processes, on the other hand, they can block the passage of immune cells into the CNS, hindering neuronal regeneration during acute local injuries. Such factors are intensified with aging, as the chronic inflammatory state present in the elderly increases the chance of developing cognitive problems, such as dementia, following immune response (CODER et al., 2017).

In analysis of several studies, the inflammatory state of the CNS was evidenced, characterized by increased inflammatory mediators such as IL-1 $\beta$, TNF-a and IL-6 produced by glia cells and peripheral senescent cells, leading to increased permeabilization of the bloodbrain barrier, which facilitates the entry of immune cells into the CNS (GROEF et al., 2015; BETTIO et al., 2017). Neuroinflammation has been characterized as an extremely important factor for the onset and progression of neurological degeneration, which will lead to modifications of neuronal structure and function, and consequent increased neuron death in the CNS (CANDIA \& MATARESE, 2018).

The CNS can also modulate the immune system through the neuroimmuno-endocrine axis. Thus, acute CNS injuries, such as stroke, can cause systemic immunosuppression, while activation of the brain reward system promotes enhancement of the immune response (CODER et al., 2017; LIANG et al., 2017). The association of neurological diseases with immune and endocrine disorders is also an important target of much research, such as recent epidemiological studies indicating a correlation between Diabetes and Alzheimer's disease (AD) (KLET, 2017; BETTIO et al., 2017). In pathological conditions, dysregulation of metabolite hormones, such as leptin and insulin, lead to increased accumulation and aggregation of tau and beta-amyloid (AB) proteins, this factor seems to further impair hippocampal synaptic plasticity and favor the onset of dementia states (CANDIA \& MATARESE, 2018).

Therefore, it is noted that immunosenescence causes premature aging of the brain and consequent memory loss. In parallel, CNS degeneration exerts negative effects on aging $T$ cells, resulting in systemic involvement cyclically with age (CODER et al., 2017).

\section{Vitamin D}

Several studies have demonstrated the role of vitamin $D$ in the human body, acting in bone and calcium metabolism. It is observed that vitamin D insufficiency is associated with the worsening of chronic diseases such as diabetes, 
metabolic disorders, cardiovascular diseases, autoimmune diseases, and even malignant diseases. Therefore, this vitamin has several functions in the body, including modulation of cell growth, neurogenesis, neuroprotection, detoxification, immune function, and reduction of inflammation (LEE et al., 2020).

Most immune cells, including monocytes, macrophages, dendritic cells (DCs), as well as T and B lymphocytes carry the vitamin $D$ receptor. Therefore, immune tolerance is promoted by its action, through DCs to stimulate the differentiation of regulatory $T$ cells (Treg) (ELMADFA \& MEYER, 2019).

Recent studies have shown certain calciferol receptor (VDR) expression on almost all cells of the immune system with anti-infective and immunomodulatory actions. Through the production of cytokines and growth factors, as well as 25(OH)D levels, the extrarenal hydroxylation of vitamin $D$ is regulated. This process is fundamental for this vitamin to act in an autocrine and paracrine manner, with functions of inhibiting cell proliferation, promoting cell differentiation and immune regulation (LEE et al., 2020).

Among the mechanisms
contributing to the anti-infective properties of this vitamin, the production of antimicrobial peptides such as cathelicidin, produced by phagocytic cells, has been reported to provide protection against bacterial infection, and to have direct antiviral effects against influenza virus. Another antiinfective property is the result of activation of phagocyte NADPH oxidase (NOX), which induces increased production of reactive oxygen species (ROS) (GONCALVES-MENDES et al., 2019).

It is also known that vitamin $D$ can switch the T cell response from $T$ helper 1 (Th1) to Th2-mediated cellular response and thus reduce inflammation and promote the immunosuppressive state. Moreover, it promotes Treg cell differentiation in vitro via an indoleamine 2,3-dioxygenase (IDO)-dependent pathway. Thus, calciferol is characterized as an important regulator of the immune response, especially in challenges of vaccines and infections (GONCALVESMENDES et al., 2019).

Immunosenescence contributes to reduced vaccine response in the elderly and is aggravated by nutrient deficiencies such as vitamin $D$, because it is a cofactor. Immune system functions are modulated by vitamin $D$ and can potentiate the innate immune response or inhibit the adaptive system and thereby modulate vaccination response (GONCALVES-MENDES et al., 2019; ELMADFA \& MEYER, 2019).

\section{Vaccination of the Elderly}

Changes in innate and adaptive immunity associated with aging decrease the effectiveness of vaccination in the elderly (WEYAND \& GORONZY, 2016). Immature $T$ lymphocytes are known to decline and are massively replaced by memory $T$ cells, which limits $T$ and $B$ responses to new pathogens and consequently increases susceptibility to infectious diseases (PERA et al., 2015). Furthermore, the decreased antigen receptor diversity and the ability to proliferate after antigen engulfment of these cells have been described as one 
of the reasons for the low vaccine response (BISCHOF et al., 2019).

Aging is marked by a reduced humoral response, from the inefficient production of naive $\mathrm{B}$ cells by the bone marrow (FUENTES et al., 2017). In this sense, memory B cells have a significantly low capacity to differentiate into plasma cells to produce specific antibodies, limiting the number of clones available to respond to novel pathogens (CROOKE et al., 2019).

However, there is a large heterogeneity regarding the ineffectiveness of vaccination in the elderly, justifying the interaction between environmental, genetic, immunological and socioeconomic factors in vaccine response. This fact is evidenced by a study that showed that older individuals residing in a nursing home are less responsive to vaccination compared to those living in the community (BARREDA et al., 2016).

\section{Among the vaccines} recommended for the elderly, the influenza, pertussis, diphtheria and tetanus vaccine, the pneumococcal vaccine, and the vaccine to prevent zoster reactivation stand out (CIABATTINI et al., 2018; BARREDA et al., 2016). In this perspective, it is observed that the response to the vaccine for pertussis and tetanus is satisfactory, even if reduced when compared to younger individuals and adults, while the vaccines aimed at pneumococcal disease and influenza show little efficacy in a considerable part of the elderly population (PINTI et al., 2016; XU \& LARBI, 2017). Cohort studies have shown that the trivalent inactivated influenza vaccine has positive results in about $60 \%$ of healthy young individuals, with a drop to $17 \%$ to $53 \%$ in the elderly (WONG et al., 2020).

The efficacy of live and attenuated zoster vaccine decreases with age, partially preventing herpes zoster reactivation or reducing the severity of post-herpetic pneumonia (PERA et al., 2015). In addition, the hepatitis $B$ vaccine has shown a significant reduction in its action in sexagenarian patients, as there is a reduction in the number of plasma cells in their bone marrow, which reduces the release of virus-specific antibodies (VENTURA et al., 2017).

Influenza infection in the elderly is characterized by high morbidity and mortality and hospital admissions (BULATI et al., 2017). It is worth noting that mortality rates for various diseases in populations over 70 years of age reach their peak in the months of annual influenza epidemics, which characterizes this as the main cause of excess mortality in the winter months in elderly patients (PERA et al., 2015). Reduced stress resistance and increased serum $\mathrm{L}-6$ levels in this population have been shown to affect susceptibility to influenza and responsiveness to the virus vaccine (GUBBELSBUPP et al., 2018; PINTI et al., 2016). Thus, it is noted that ineffective response to vaccination can have serious consequences, leading to a high mortality rate (BEKTAS et al., 2017).

The changes that occur in these cells with age, such as decreased functional capacity - including chemotaxis functions, phagocytosis, signaling, and antigen presentation to $T$ cells - and exacerbated cytokine production, affect vaccine efficacy (CIABATTINI et al., 2018). In other words, immunosenescence affects all stages of 
vaccine responses, from the innate immune system to antibody and memory responses, as the adaptive system also undergoes changes (AUTRAN, 2019).

Therefore, hyporesponsiveness to vaccination is a barrier in maintaining healthy aging, increasing the risk of subsequent infection in this age group (XU \& LARBI, 2017). In this scenario, it is observed that some vaccines with formulations suitable for the elderly have already been developed, as in the case of influenza and zoster, and others are in trials (COOKENHAM et al., 2020).

\section{Elderly vaccination calendar}

The higher number of infectious diseases cases in this age group compared to young adults reflects the fragility of the senescent immune system (WEYAND \& GORONZY, 2016). The impaired ability to defend against invading antigens makes vaccination one of the most effective methods for disease prevention (BARREDA et al., 2016). However, the vaccine response is also affected with immunosenescence due to a lower antibody production. (BULATI et al., 2017).

It is noticeable that some population groups suffer from undervaccination for different reasons, such as misconceptions about safety, cost, and inability of health systems to ensure that these patients receive the recommended vaccines (DOHERTY et al., 2016). In this sense, one example is the elderly, who, even though they are the most susceptible to vaccine-preventable diseases and have a higher mortality rate, become even more vulnerable (CIABATTINI et al., 2018).
This global-scale problem requires vaccination strategies. Thus, the World Health Organization (WHO) recommends annual vaccination of people 65 years of age and older with seasonal inactivated influenza vaccine. Although the effectiveness of influenza vaccination is reduced in the elderly, it remains the most effective public health tool available to protect older people against the disease (DOHERTY et al., 2016).

Awareness about the importance of vaccination in this age group is essential for the desired adherence (ALVES \& BUENO, 2019; XU \& LARBI, 2017). From this perspective, public education campaigns can be conducted, introducing appropriate operational structures and new vaccine formulations that improve immune responses with additional adjuvants, dose increases or other changes in vaccine composition (BULATl et al., 2017; DOHERTY et al., 2016). Adjuvants can increase the speed and efficacy of the development of immune responses, decreasing vaccine dose and low responsiveness in the elderly, and increasing the ability to cross-protect (CIABATTINI et al., 2018).

The vaccination schedule for the elderly recommended by the Brazilian Immunization Society (Chart 1) includes the vaccines required. It is important to emphasize that the contraindications are, in general, the same as for other ages, such as avoiding vaccines with live attenuated organisms for immunodeficient people or those using immunosuppressants.

\section{CONCLUSION}

Given the above, the immune system has an important function in 
protecting the body against external agents. Therefore, its proper functioning is important for tissue repair, wound healing, elimination of dead and cancer cells and formation of the intestinal microbiota. Within this context, aging induces changes in innate and adaptive immune function, affecting both the performance of tasks and the number of immune cells, making the elderly more susceptible to infections and long-term complications.

During immunosenescence, antigen uptake, processing and presentation, as well as T cell defects, trigger less effective immune responses. Furthermore, the increase in pro-inflammatory cytokines contribute to the chronic inflammatory process, contributing to impaired vaccine responses as they are measured by antibody production. Despite these factors, the need for the act of vaccination is fundamental in the elderly, as it strengthens immune responses and improves clinical outcomes.

Illustration 1 - Selection of articles
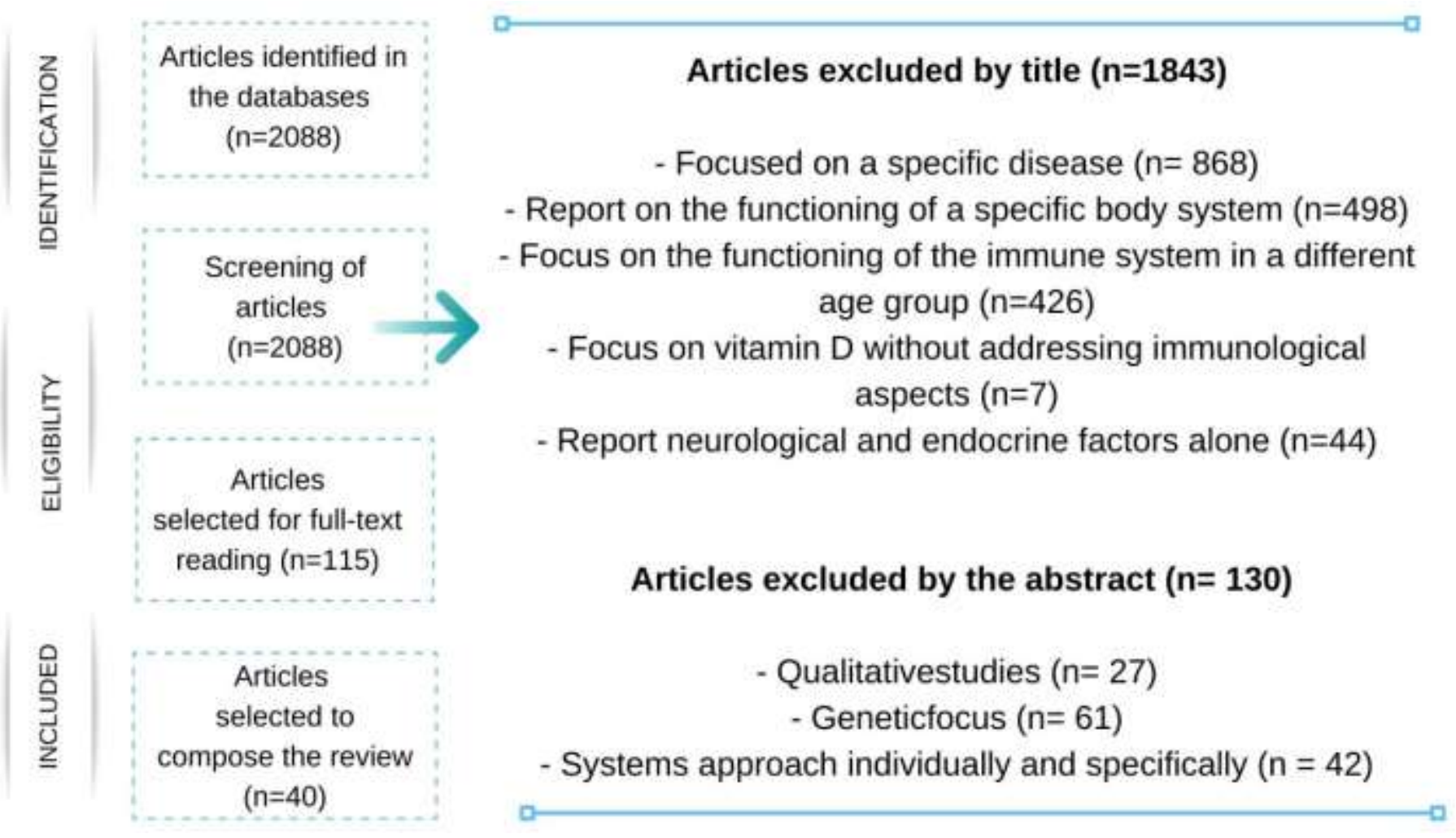

Source: Research Authors.

Caption: Using the Medline (via PubMed), LILACS (via BVS), and ScienceDirect databases, after applying the eligibility criteria during the selection of the titles, abstracts, and most pertinent texts, $1.91 \%$ of the articles were selected to compose the review. 
Illustration 2- Predominance of different types of immune responses against viral antigens during the individual's lifetime associating cell types.

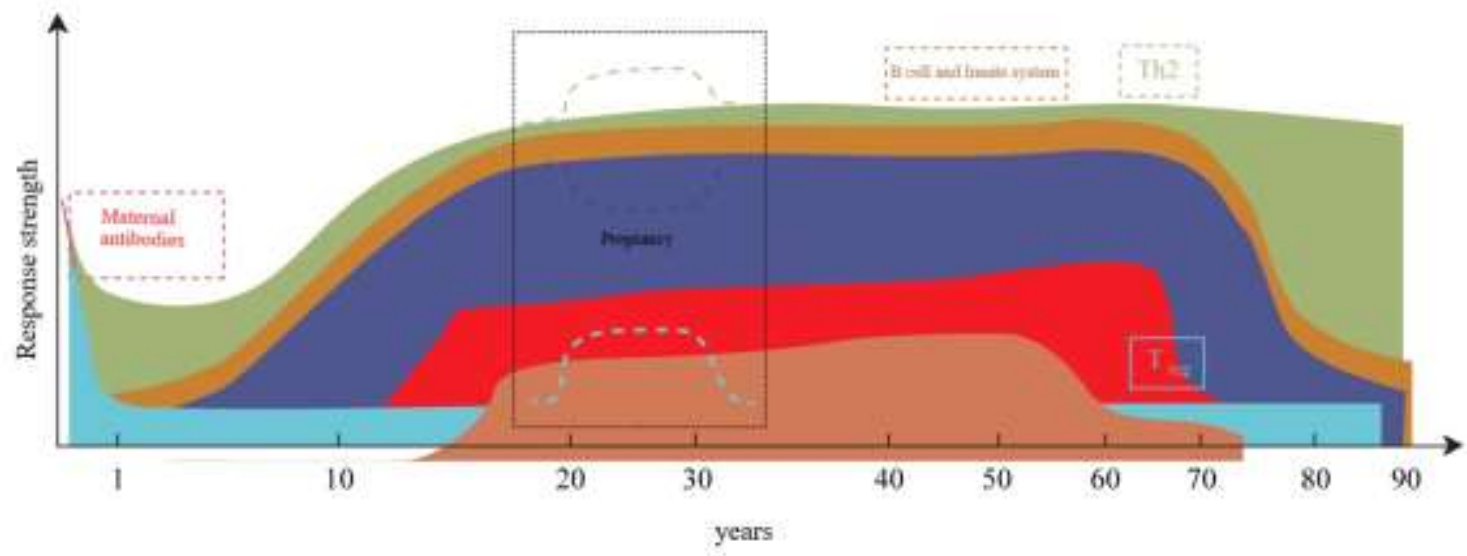

Source: Research Authors.

Caption: Strength analysis of cellular components response from the innate and adaptive immune systems in relation to age in years. Thus, demonstrating the changes in the level of cell functionality throughout the process of immunosenescence.

Illustration 3- Changes in the body associated with aging and their consequences.
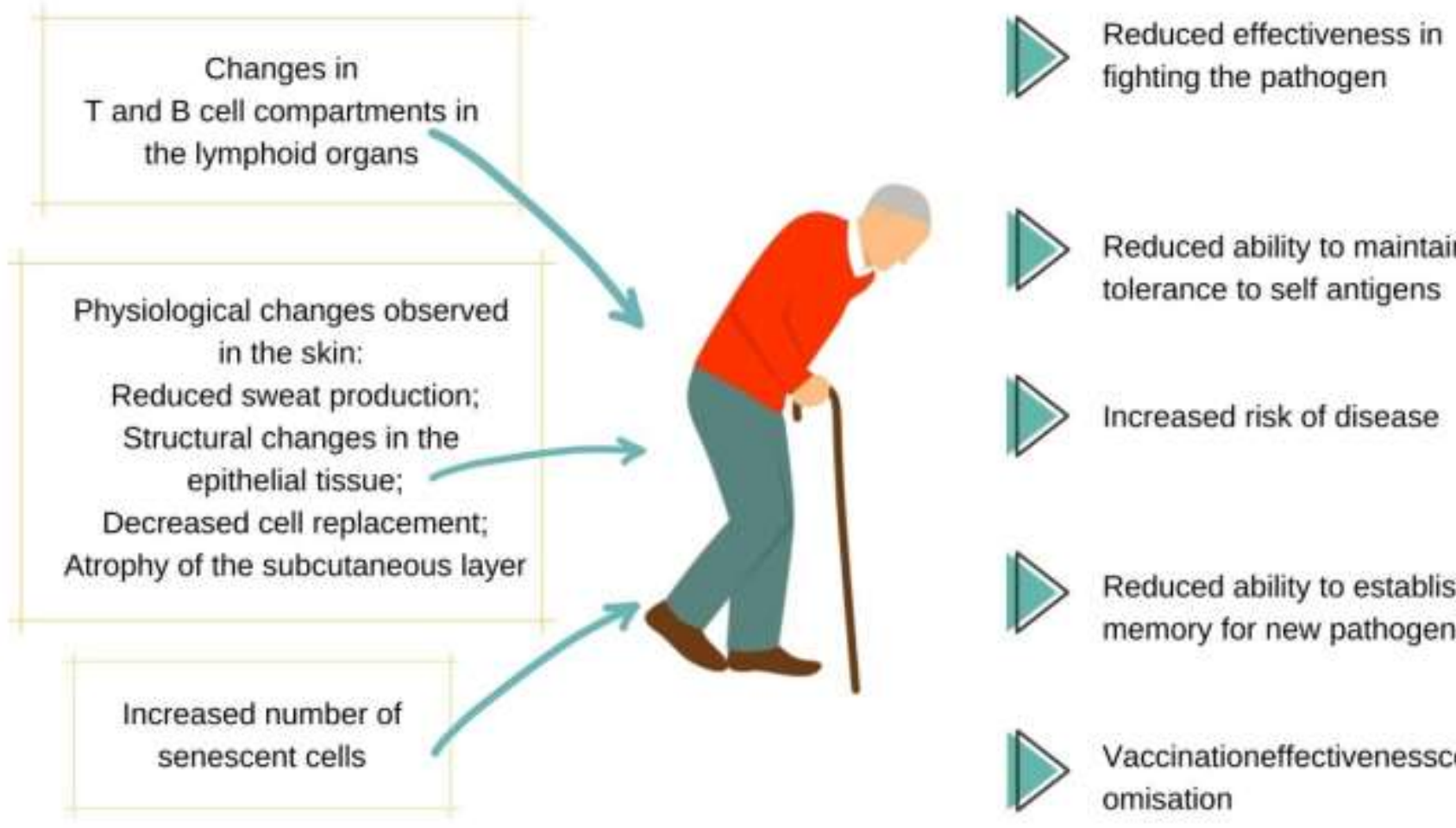

fighting the pathogen

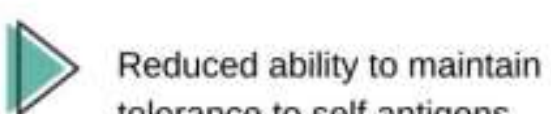

tolerance to self antigens

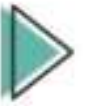

Increased risk of disease

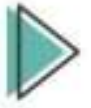

Reduced ability to establish memory for new pathogens

Vaccinationeffectivenesscompr omisation

Source: Research Authors.

Caption: Representation of the main impacts on the body during the the immune system aging process 2021 March Edition | www.jbino.com | Innovative Association 
Illustration 4- Immunosenescence impact on immune system cells

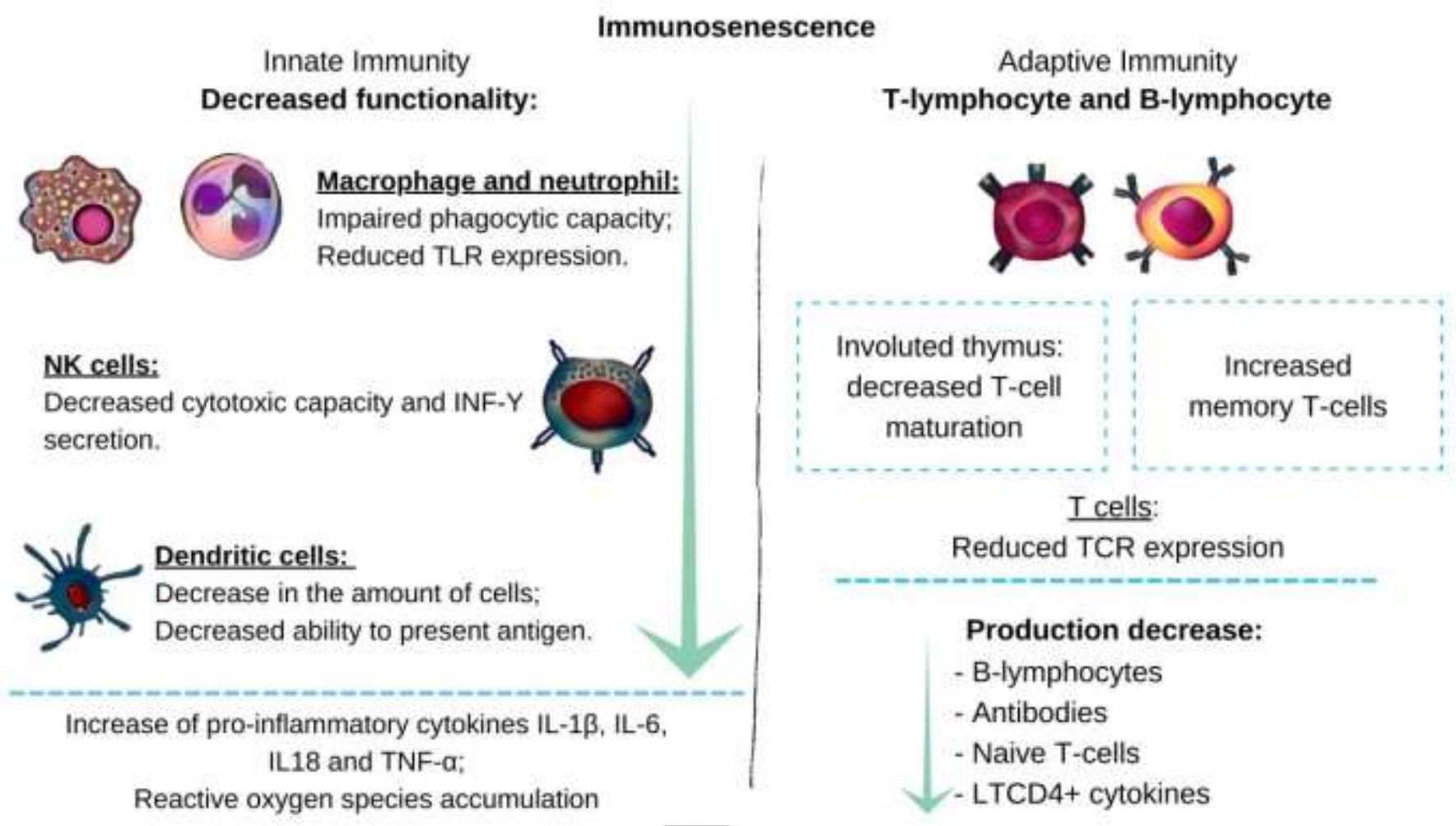

Source: Research autors.

Caption: Immunosenescence consequences on the immune system cells, relating to the increase or decrease in their normal functions. Toll-like receptors (TLR); Natural-Killers Cells (NK Cells); Interferon-gamma (INF- $\gamma$ ); Interleukin 1 beta (IL-1 $\beta$ ); Interleukin 6 (IL-6); Interleukin 18 (IL-18); Tumor Necrosis Factor Alpha (TNF- $\alpha$ ); T-cell receptor (TCR); T helper lymphocyte (LTCD4+). 
Chart 1- Elderly population (60 years or older) vaccination schedule according to the Brazilian Society of Immunizations (SBIm)

\begin{tabular}{|c|c|c|}
\hline Vaccines & Referral & Schemes and recommendations \\
\hline Influenza & Routine & Annual Single Dose. \\
\hline $\begin{array}{l}\text { Pneumococcal } \\
\text { (VPC13) and (VPP23) }\end{array}$ & Routine & $\begin{array}{l}\text { Start with one dose of PCV } 13 \text { followed by } \\
\text { one dose of PPV } 23 \text { six to } 12 \text { months later, } \\
\text { and a second dose of PPV } 23 \text { five years } \\
\text { after the first }\end{array}$ \\
\hline Herpes zoster & Routine & One dose. \\
\hline $\begin{array}{l}\text { Acellular bacterial } \\
\text { triple adult type } \\
\text { (diphtheria, tetanus, } \\
\text { and pertussis) - dTpa } \\
\text { or dTpa-VIP } \\
\text { Double adult type } \\
\text { (diphtheria and } \\
\text { tetanus) - dT }\end{array}$ & Routine & $\begin{array}{l}\text { Update dTpa regardless of previous interval } \\
\text { with dT or TT. } \\
\text { Complete basic vaccination scheme: } \\
\text { booster with dTpa every ten years. } \\
\text { Incomplete basic vaccination scheme: } \\
\text { one dose of dTpa at any time and complete } \\
\text { the basic vaccination with one or two doses } \\
\text { of dT (double bacterial vaccine of the adult } \\
\text { type) in order to total three doses of vaccine } \\
\text { containing the tetanus component. } \\
\text { Unvaccinated and/or unknown } \\
\text { vaccination history: one dose of dTpa and } \\
\text { two doses of dT in the schedule } 0-2-4 \text { to } \\
8 \text { months. }\end{array}$ \\
\hline \multirow{3}{*}{ Hepatitis A e B } & $\begin{array}{l}\text { Hepatitis A: after } \\
\text { serological evaluation } \\
\text { or in exposure or } \\
\text { outbreaks situations }\end{array}$ & Two doses, 0 - 6 months. \\
\hline & Hepatitis B: routine. & Three doses, 0 - 1 - 6 months. \\
\hline & $\begin{array}{l}\text { Hepatitis A and B: } \\
\text { when both vaccines } \\
\text { are recommended }\end{array}$ & Three doses, 0 - 1 - 6 months. \\
\hline Yellow Fever & $\begin{array}{l}\text { For unvaccinated } \\
\text { elderly and residents } \\
\text { in vaccination areas, } \\
\text { after risk/benefit } \\
\text { assessment }\end{array}$ & $\begin{array}{l}\text { Single dose. There is no consensus about } \\
\text { the duration of protection conferred by the } \\
\text { vaccine. According to the epidemiological } \\
\text { risk, a second dose may be considered due } \\
\text { to the risk of vaccine failure. }\end{array}$ \\
\hline $\begin{array}{l}\text { Meningococcal } \\
\text { conjugates ACWY/C }\end{array}$ & $\begin{array}{l}\text { Increased risk } \\
\text { situations. }\end{array}$ & $\begin{array}{l}\text { One dose. The vaccine indication, as well } \\
\text { as the need for boosters, will depend on the } \\
\text { epidemiological situation. }\end{array}$ \\
\hline $\begin{array}{l}\text { Triple viral strain } \\
\text { (measles, mumps and } \\
\text { rubella) }\end{array}$ & $\begin{array}{l}\text { Increased risk } \\
\text { situations }\end{array}$ & $\begin{array}{l}\text { One dose. Vaccine indication depends on } \\
\text { the epidemiological risk and individual } \\
\text { susceptibility status. }\end{array}$ \\
\hline
\end{tabular}


Source: Adapted from the Brazilian Immunization Society.

Caption: Schemes and recommendations of the main vaccines aimed at the elderly population, as well as comments about them.

\section{REFERENCES}

1. Akha AAS. Aging and the immune system: An overview. J immunol methods, v. 463, p. 21-26, 2018.

2. Alves AS, Bueno V. Immunosenescence: participation of $T$ lymphocytes and myeloid-derived suppressor cells in agingrelated immune response changes. Einstein, v. 17, n. 2, 2019.

3. Autran B. Alterations in responses to vaccines in older people. Rev Mal Respir, v. 36, n. 9, p. 1047-1056, 2019.

4. Barreda DR, Neely HR, Flajnik MF. Evolution of Myeloid Cells. Microbiol Spectr, v. 4, n. 3, 2016.

5. Baver ME, Fuente MDF. The role of oxidative and inflammatory stress and persistent viral infections in immunosenescence. Mech Ageing Dev, v. 158, p. 27-37, 2016.

6. Bektas A, Schurman SH, Sen R, Ferrucci L. Human $T$ cell immunosenescence and inflammation in aging. J Leukoc Biol, $v$. 102, n. 4, p. 977-988, 2017.

7. Bettio LE, Rajendran L, Gil-Mohapel J. The effects of aging in the hippocampus and cognitive decline. Neurosci Biobehav Rev, v. 79, p. 66-86, 2017.

8. Bischof J, Gartner F, Zeiser K, Kunz R, Schreiner C, Hoffer E, Burster T, Knippschild $U$, Zimecki $M$. Immune Cells and Immunosenescence. Folia Biol, v. 65, n. 2, p. 53-63, 2019.

9. Brazilian Society of Immunizations (SBIm) 2020/2021. Elderly SBIm vaccination schedule. Available http://sbim.org.br/images/calendarios/c alend-sbim-idoso.pdf.

10. Bulati M, Caruso C, Colonna-Romano G. From lymphopoiesis to plasma cells differentiation, the age-related modifications of $B$ cell compartment are influenced by "inflamm-ageing". Ageing Res Ver, v. 36, p. 125-136, 2017.

11. Candia P, Matarese G. Leptin and ghrelin: sewing metabolism onto neurodegeneration.

Neuropharmacology, v. 136, p. 307-316, 2018.

12. Cepeda S, Griffith AV. Thymic stromal cells: Roles in atrophy and ageassociated dysfunction of the thymus. Exp Gerontol, v. 105, p. 113-117, 2018.

13. Ciabattini A, Nardini C, Santoro F, Garagnani P, Franceschi C, Medaglini D. Vaccination in the elderly: The challenge of immune changes with aging. Semin Immunol, v. 40, p. 83-94, 2018.

14. Coder B, Wang W, Wang L, Wu Z, Zhuge Q, Su DM. Friend or foe: the dichotomous impact of $T$ cells on neuro-de/regeneration during aging. Oncotarget, v. 8, n. 4, p. 7116-7137, 2017.

15. Cookenham T, Lanzer KG, Gage E, Lorenzo EC, Carter D, Coler RN, Baldwin SL, Haynes L, Reiley WW, Blackman MA. Vaccination of aged mice with adjuvanted recombinant influenza nucleoprotein enhances protective immunity. Vaccine, v. 38, n. 33, p. 52565267, 2020.

16. Crooke SN, Ovsyannikova IG, Poland GA, Kennedy RB. Immunosenescence and 
human vaccine immune responses. Immun Ageing, v. 16, p. 25, 2019.

17. Doherty M, Schmidt-Ott R, Santos Jl, Stanberry LR, Hofstetter AM, Rosenthal SL, Cunningham AL. Vaccination of special populations: Protecting the vulnerable. Vaccine, v. 34, n. 52, p. 6681-6690, 2016.

18. Elmadfa I, Meyer AL. The Role of the Status of Selected Micronutrients in Shaping the Immune Function. Endocr Metab Immune Disord Drug Targets, v. 19, n. 8, p. 1100-1115, 2019.

19. Fuentes E, Fuentes M, Alarcón M, Palomo I. Immune System Dysfunction in the Elderly. An Acad Bras Ciênc, v. 89, n. 1, p. 285-299, 2017.

20. Fülöp T, Dupuis $G$, Witkowski JM, Larbi A. The Role of Immunosenescence in the Development of Age-Related Diseases. Ver Invest Clin, v. 68, n. 2, p. 84-91, 2016.

21. Goncalves-Mendes N, Talvas J, Dualé C, Guttmann A, Corbin V, Marceau G, Sapin $V$, Brachet P, Evrard B, Laurichesse H, Vasson MP. Impact of Vitamin $D$ Supplementation on Influenza Vaccine Response and Immune Functions in Deficient Elderly Persons: A Randomized Placebo-Controlled Trial. Front Immunol, v. 10, p. 65, 2019.

22. Groef L, Dekeyster E, Moons L. The zebrafish as a gerontology model in nervous system aging, disease, and repair. Ageing Res Ver, v. 24, p. 358-368, 2015.

23. GubbelsBupp MR, Potluri T, Fink AL, Klein SL. The Confluence of Sex Hormones and Aging on Immunity. Front Immunol, v. 9, p. 1269, 2018.

24. Hotamisligil GS. Inflammation, metaflammation and immunometabolic disorders. Nature, v. 542, n. 7640 , p. $177-$ 185, 2017.
25. Joachim RB, Kobzik L. Why are children more resistant to mortality from severe infections? Future Microbiol, v. 13, p. 1549-1552, 2018.

26. Kloet R. Stress and brain aging: role of glucocorticoid and mineralocorticoid hormones.

Reference

Module

Neuroscience and Biobehavioral Psychology, 2017.

27. Lee DH, Chon J, Kim Y, Seo YK, Park EJ, Won CW, Soh Y. Association between vitamin $D$ deficiency and cognitive function in the elderly Korean population: A Korean frailty and aging cohort study. Medicine (Baltimore), v. 99, n. 8, 2020.

28. Liang Z, Zhao Y, Ruan L, Zhu L, Jin K, Zhuge $Q$, Su DM, Zhao Y. Impact of aging immune system on neurodegeneration and potential immunotherapies. Prog Neurobiol, v. 157, p. 2-28, 2017.

29. Majumdar S, Nandi, D. Thymic Atrophy: Experimental Studies and Therapeutic Interventions. Scand J Immunol, v. 87, n. 1, p. 4-14, 2018.

30. Odinokov D, Hamblin MR. Aging of lymphoid organs: Can photobiomodulation reverse ageassociated thymic involution via stimulation of extrapineal melatonin synthesis and bone marrow stem cells? J Biophotonics, v. 11, n. 8, 2018.

31.Page AL, Dupuis G, Larbi A, Witkowski JM, Fulop T. Signal transduction changes in CD4 + and CD8 + T cell subpopulations with aging. Exp Gerontol, v. 105, p. 128139, 2018.

32. Patel SY, Carbone J, Jolles S. The Expanding Field of Secondary Antibody Deficiency: Causes, Diagnosis, and Management. Front Immunol, v. 10, p. 33 , 2019. 
33. Pawelec G. Age and immunity: What is "immunosenescence"? Exp Gerontol, v. 105, p. 4-9, 2018.

34. Pera A, Campos C, López N, Hassouneh $\mathrm{F}$, Alonso C, Tarazona R, Solana R. Immunosenescence: Implications for response to infection and vaccination in older people. Maturitas, v. 82, n. 1, p. 5055, 2015.

35. Pinti $M$, Appay V, Campisi J, Frasca $D$, Fülöp T, Delphine $M$, Larbi A, Weinberg B, Cossarizza A. Aging of the immune system: Focus on inflammation and vaccination. Eur J Immunol, v. 46, n. 10, p. 2286-2301, 2016.

36. Schaenman JM, Rossetti M, Sidwell T, Groysberg V, Sunga $G$, Korin $Y$, Liang $E$, Zhou X, Abdalla B, Lum E, Bunnapradist S, Pham T, Danovitch G, Reed EF. Increased $T$ cell immunosenescence and accelerated maturation phenotypes in older kidney transplant recipients. Hum Immunol, v. 79, n. 9, p. 659-667, 2018.
37. Simon AK, Hollander GA, McMichael A. Evolution of the immune system in humans from infancy to old age. Proc Biol Sci, v. 282, n. 1821, p. 2014-3085, 2015.

38. Ventura MT, Casciaro M, Gangemi $S$, Buquicchio R. Immunosenescence in aging: between immune cells depletion and cytokines up-regulation. Clin Mol Allergy, v. 15, p. 21, 2017.

39. Weyand CM, Goronzy JJ. Aging of the Immune System. Mechanisms and Therapeutic Targets. Ann Am Thorac Soc, v. 13, n. 5, p. 422-428, 2016.

40. Wong GCL, Strickland MC, Larbi A. Changes in $T$ Cell Homeostasis and Vaccine Responses in Old Age. Interdiscip Top Gerontol Geriatr, v. 43, p. 36-55, 2020.

41.XU W, Larbi A. Markers of T Cell Senescence in Humans. Int $\mathbf{J}$ Mol Sci, $\mathbf{V}$. 18, n. 8, p. 1742, 2017. 